\title{
Paullu y Manco ¿una diarquía inca en tiempos de conquista?
}

Paullu et Manco, une diarchie inca aux temps de la conquête?

Paullu and Manco: an Inca diarchy at the time of the Conquest?

\section{Ximena Medinaceli}

\section{(2) OpenEdition}

Journals

Edición electrónica

URL: http://journals.openedition.org/bifea/3853

DOI: $10.4000 /$ bifea.3853

ISSN: 2076-5827

Editor

Institut Français d'Études Andines

Edición impresa

Fecha de publicación: 1 agosto 2007

Paginación: 241-258

ISSN: 0303-7495

Referencia electrónica

Ximena Medinaceli, «Paullu y Manco ¿una diarquía inca en tiempos de conquista? », Bulletin de I'Institut français d'études andines [En línea], 36 (2) | 2007, Publicado el 01 febrero 2008, consultado el 01 diciembre 2020. URL : http://journals.openedition.org/bifea/3853 ; DOI : https://doi.org/10.4000/ bifea.3853

\section{(c) $(1)$}

Les contenus du Bulletin de l'Institut français d'études andines sont mis à disposition selon les termes de la licence Creative Commons Attribution - Pas d'Utilisation Commerciale - Pas de Modification 4.0 International. 


\title{
Paullu y Manco iuna diarquía inca en tiempos de conquista?
}

\section{Ximena Medinaceli*}

\begin{abstract}
Resumen
Este trabajo se pregunta cuál fue la relación del Inca Paullu con la región del Collasuyu a la que ingresó como garantía para que los pueblos no se levanten durante el ingreso tanto de Diego de Almagro (1535) como de Gonzalo Pizarro (1538) durante el periodo de la conquista española de la región sur del imperio de los incas. Indagar sobre este punto nos llevó a replantear las preguntas acerca de la relación entre Paullu, que colaboró con los españoles, y su hermano Manco, que se resistió a ellos en Vilcabamba. La propuesta de este trabajo es que ambos - a pesar de lo conflictivo del periodo- actuaron conociendo lo que hacía uno y otro estando siempre en contacto. Es decir que podría estar funcionando, bajo condiciones dramáticas, la famosa diarquía inca planteada por autores como Zuidema y Duviols.
\end{abstract}

Palabras clave: conquista española, diarquía incaica, Paullu Inca, Manco Inca, Francisco Tito Yupanqui, Collasuyu

\section{Paullu et Manco, une diarchie inca aux temps de la conquête?}

\section{Résumé}

Cet article se demande quelle fut la relation entre l'Inca Paullu et le Collasuyu, région où il s'est rendu pour servir de garantie afin que les peuples ne se soulèvent pas au cours de l'arrivée aussi bien de Diego de Almagro (1535) que de Gonzalo Pizarro (1538) au cours de la conquête espagnole dans la région sud de l'empire Inca. Une recherche sur ce thème nous conduit à reconsidérer les questions autour des relations entre Paullu, qui collabora avec les espagnols, et son frère Manco qui résista à Vilcabamba. Nous pensons que chacun —-bien que cette époque ait été conflictuelle- connaissait parfaitement les agissements de l'autre et qu'ils ont été en contact permanent. Cela signifie que la fameuse diarchie inca aurait pu fonctionner, dans des conditions dramatiques, comme le supposent des auteurs comme Zuidema et Duviols.

Mots clés : conquête espagnole, diarchie incaïque, Paullu Inca, Manco Inca, Francisco Tito Yupanki, Collasuyu

* Carrera de Historia, Instituto de Estudios Bolivianos (ambas de la Universidad Mayor de San Andrés), Coordinadora de Historia, Sociedad Boliviana de la Historia, Academia Boliviana de la Historia. E-mail: xmedinaceli@hotmail.com 


\title{
Paullu and Manco: an Inca diarchy at the time of the Conquest?
}

\begin{abstract}
This work examines the nature of Inca Paullu's relationship with Collasuyo that led Diego de Almagro (1535) and Gonzalo Pizarro (1538) to take him during the Spanish Conquest to the southern region of the Inca Empire. The research on this issue leads us to reformulate questions about the relationship between Paullu, who collaborated with the Spaniards, and his brother Manco, who resisted them in Vilcabamba. It is suggested that both of them - in spite of the conflicts of the time - acted knowing about what the other was doing and constantly being in touch with each other. In this case, the famous Inca diarchy, suggested by Zuidema and Duviols could have been working under dramatic conditions.
\end{abstract}

Key words: spanish conquest, Inca Diarchy, Paullu Inca, Francisco Tito Yupanqui, Collasuyo

La pregunta de rigor es por qué retomar un tema como el de la sucesión inca en el momento de la invasión europea, tema tan estudiado — y se pensó agotado- ya en la década de 1930, cuando se realizaron importantes estudios sobre la descendencia de Huayna Capac. Estos trabajos estuvieron favorecidos por una profusa documentación sobre esta coyuntura histórica, pero que, sin embargo, estuvieron influenciados por una visión maniquea de la historia, visión que ha marcado nuestra manera de juzgar a los actores, particularmente de la élite inca. Estamos pensando sobre todo en los trabajos de Ella Dumbar Temple (1937; 1939; 1940; 1948), Nathan Wachtel (1976), Waldemar Espinoza Soriano (1969), Manuel Burga (1988), Roberto Santos (1987; 1989) y algunos otros estudiosos sobre este periodo. La mayoría de ellos clasifican a los indios según su actuación como «colaboracionistas» o «rebeldes». Algunas veces los términos utilizados son más duros, pues al referirse a Paullu lo califican como «traidor a su raza» o «inca títere» (Dumbar Temple, 1937; 1939; 1948; Wachtel, 1971; Burga, 19881). Por otra parte, los estudios sobre este periodo ignoran o minimizan la situación del cuarto sur del imperio, el Collasuyu.

Nuestra intención entonces es, a partir de una biografía de Paullu enfocada en su actuación en el Collasuyu, intentar una lectura de este crucial periodo de nuestra historia, saliéndonos de una visión en blanco y negro. Concretamente, como sugerimos en el título, nos guiamos por la hipótesis de un ejercicio compartido del poder de los dos Incas descendientes: Manco y Paullu2.

1 El interés del estudio de esta coyuntura es muy antiguo. Desde el siglo XIX, autores como José Toribio Medina se dedicaron a publicar documentos sobre el temprano siglo XVI. A comienzos del siglo XX destaca el trabajo de Ella Dumbar Temple quien publicó a lo largo de una década (entre 1939 y 1948) trabajos acerca de la descendencia de Wayna Capac enfatizando en Paullu. En épocas posteriores, Wachtel y Burga (1976 y 1988 respectivamente) presentaron interpretaciones globales trabajando el tema de la Conquista, asimismo Espinoza Soriano. Una de las investigaciones más difundidas es la de Hemming (1970) que tiene una particular posición, está muy bien documentada y claramente escrita. En Bolivia, hay pocos pero importantes trabajos. En primer lugar el libro de Arze Quiroga (1969), entendiendo que allí están los orígenes de la sociedad boliviana y, desde otra perspectiva, la tesis doctoral de Barnadas sobre Charcas (1973). A pesar de los pocos estudios bolivianos, se trata de un periodo de amplio dominio de los intelectuales de mediados de siglo. Una prueba de ello son los debates acerca de la fecha de la fundación de Chuquisaca que requería un dominio de las fuentes y los hechos de las primeras décadas coloniales (Mendoza, 1938). A pesar de ello, encontramos dos vacíos importantes, por una parte una menor atención a los sucesos ocurridos en el Collasuyu, y por otra y si los hay, existe una ausencia de análisis de su particularidad e incidencia en los procesos más globales. De este modo este momento fundacional no está suficientemente estudiado en nuestra región para entender mejor, precisamente estos orígenes a los que apelan los títulos tanto de Arze Quiroga como de Barnadas.

2 El historiador argentino Gonzalo Lamana, más recientemente que los otros autores (1996), hizo una propuesta distinta a la de los investigadores antes citados, con la cual coincidimos en gran parte aunque no en la totalidad de su argumento. El plantea que la conquista de la nobleza inca no se debe ver como un proceso dividido entre pro 
La figura de Paullu es sumamente atractiva precisamente por haber sido el blanco de los juicios históricos negativos pero cuyo papel —entre 1534 y 1539— puede ser leído con distinta perspectiva. De hecho Paullu colaboró primero con Almagro, luego con Pizarro y finalmente fue partidario de Cristóbal Vaca de Castro con cuyo nombre fue bautizado en 1543. Recibió encomiendas, tierras y tuvo una vida ostentosa en su residencia de Colcampata en el Cusco (Dumbar Temple, 1932; 1933; 1948; Wachtel, 1971).

\section{PAULLU TUPA INCA}

Paullu era uno de los hijos de Huayna Capac y participó como personaje central en el periodo de la Conquista, periodo donde, como un río que se introduce al mar, no se distinguen las diferencias entre lo que viene de tiempos prehispánicos de las situaciones nuevas. Todo esto cruzado por enormes y violentas transformaciones.

Después de la ejecución de Atahuallpa, se nombró como Inca a Tupac Huallpa, pero como fue asesinado a los pocos meses de su reinado tomó la mascaypacha Manco Inca, un hijo muy joven de Huayna Capac y, como era costumbre, sus parientes llegaron a rendirle homenaje y reconocer su mando. Encontramos por primera vez referencias sobre Paullu, hermano de Manco, cuando llega al Cusco desde el sur. Paullu se encontraba en el Collasuyu, porque había estado refugiado en la Isla del Sol cuando tuvieron lugar las luchas entre Huascar y Atahuallpa.

Algunos datos relacionan a Paullu con el Collasuyu de manera muy particular. Varios cronistas sostienen que Paullu era muy considerado en esta región y por este motivo acompañó a Almagro en su expedición por el Collasuyu hasta Chile. ¿Qué hacía que Paullu fuera respetado en el Collasuyu? Algunos elementos sueltos nos pueden dar una idea de las bases de su ascendencia en esa región.

En el momento de la invasión española Paullu, junto con otros nobles incas de la misma generación, se había refugiado en la Isla del Sol ante la amenaza de muerte debido a las luchas internas de los incas. Luego salió hacia el Cusco con algunos de ellos, hombres y mujeres, a rendir homenaje a su hermano Manco cuando fue reconocido como Inca por Francisco Pizarro (Quipucamayos, en Carillo, 1991 [1542]: 27).

Paullu nació alrededor de 1516; tendría entonces unos 19 años cuando acompañó a Almagro al Collasuyu, en 1535. Era solamente unos meses menor que Manco Inca. Según la probanza presentada por Paullu en 1540, era hijo del Inca Huayna Capac y de Añas Colque, mujer noble de la provincia de Huailas, pero no la esposa principal3. Paullo Topa Inga, como lo nombran los Quipucamauyos (Quipucamayos, en Carillo, 1991 [1542]: 27) era un joven, como se evidenciará luego, con una gran inteligencia y una sólida formación como seguramente ocurría con los miembros de la élite inca. Sabía de estrategias de guerra, de diplomacia y supo mantener un don de mando ante indígenas y españoles.

Paullu se quedó en el Cusco y tuvo allí dos hijos: don Felipe y don Carlos. Respecto al origen de la esposa de Paullu hay alguna controversia cuya aclaración permite comprender mejor su figura y su status en la sociedad indígena. Prácticamente todas las fuentes que hablan del

españoles vs. pro indios; más bien propone que la «identidad que orientó su acción y se mantuvo incólume a lo largo de todo el periodo (1533-1550) fue la de formar parte de una élite» que debía legitimarse en la nueva situación y tanto Paullu como Manco buscaban esta legitimidad por medios distintos y competían por ella. Coincidimos en la idea de la búsqueda de legitimidad pero discrepamos en que los dos Incas competían por el poder.

3 Varios autores coinciden en que Paullu era hijo de Huayna Capac y Añas Colque, por ejemplo los Quipucamayos y el libro Nobiliario Incásico (citado por Dumbar Temple, 1937: 108 y 127); asimismo en el Discurso sobre la descendencia de los Incas y en el memorial que presentó el hijo de Paullu don Carlos Inca. Pedro Pizarro, también nombra a Añas Colque sin embargo dice que era una india yauyo «que por ser bastardo y muy muchacho, [Huayna Capac] no hizo caso de él» (Pizarro, 1986 [1572]:102). Por su parte Murúa considera como madre de Paullu a doña Juana Carba Colqui, hija de Apu Vacapilli Titu Achandi «belicoso gran hombre de guerra» e indica que fue india de los Lares (Murúa, 1962: 112). Estos datos diversos demuestran que, contrariamente a lo que se podía pensar, la línea materna no queda clara cuando se trata del mundo indígena prehispánico. 
tema (Cobo, Sarmiento, los Quipucamayos y Sahuaraura4, in Dumbar Temple, 1937: 117-118) indican que su mujer era Tocto Usica o Tocto Sisa que luego fue bautizada como doña Catalina. Por otra parte, Ramos Gavilán, cronista de Copacabana, afirma que la mujer de Paullu era hija de Huayna Capac5, por tanto hermana de Paullu, pero Dumbar Temple que ha trabajado exhaustivamente la vida de Paullu sostiene que es imposible que Tocto Sisa fuera hija de Huayna Capac. La autora se basa en datos de la probanza del nieto de Paullu, Melchor Carlos Inca y en numerosos documentos inéditos; allí se indica que la mujer de Paullu era descendiente de Inca Roca y miembro del Ayllu Vicaquirao y por tanto no era hija de Huayna Capac. Su unión con Paullu que debió remontarse a 1537, presunta fecha de nacimiento del mayor de sus hijos (Dumbar Temple, 1948: 136). ¿Por qué entonces Ramos Gavilán, cronista bien informado, que conoció a parientes de Paullu en Copacabana sostiene lo contrario?

La versión de Ramos dice:

«El Inga Guaynacapac, fue el que más nombre dio a la isla Titicaca y a las demás convecinas porque se aventajó a su padre, y así por señalarse de dos hijas que tuvo en el Cusco, la una dellas mandó traer a esta isla y la puso en una de las casas de la Vírgenes dedicadas al Sol y que como prefecta y mayor cuidase de las demás. Cuando los españoles habían entrado ya en la tierra, uno de los hijos de Guaynacapac que estaba en el Cusco, llamado Paullo Topa Inga, vino a este asiento de Copacabana en busca de su hermana y al modo y usanza de los Ingas (sacándola del recogimiento) se casó con ella y tuvo algunos hijos y esta es causa de que muchos Indios de Copacabana se aventajan en la nobleza a los demás. (...) yo he visto algunas de las ejecutorias dadas por el emperador Carlos V de los parientes muy allegados a la Coya Doña María Pillcosisa, bisnieta de Guaynacapac Inga que murió el año 1617 en Copacabana» (Ramos Gavilán, 1988 [1621]: 185. El subrayado es nuestro).

Queda claro, entonces, que Paullu se había casado antes de ir al Cusco y que sus descendientes estaban en Copacabana, pero no tenemos el nombre de dicha esposa-hermana. Queda por tanto la posibilidad que la esposa salida del Acllawasi no fuera la misma con quien Paullu tuvo sus hijos, esto es que Tocto Sisa con quien Paullu vivía en el Cusco no era la misma que salió del Acllawasi. Sabemos que los hijos de doña Catalina Tocto Sisa fueron Carlos y Felipe que se criaron en el Cusco y no en Copacabana. Es decir, Paullu se habría casado con su hermana en Copacabana antes de ir al Cusco a encontrarse con Manco Inca — como dice la fuente- pero luego se habría unido a doña Catalina con quien formalizó su relación mucho tiempo después. Se casó públicamente con doña Catalina según sus usos gentilicios antes de la llegada de Vaca de Castro (1542) y luego se casó por la iglesia poco antes de morir (Dumbar Temple, 1948: 138).

Entonces, como debía ocurrir entre la nobleza andina, Paullu tuvo más de una esposa, su hermana sería la primera y doña Catalina, más bien una esposa secundaria, aunque en el fondo la esposa principal. La controversia quedaría resuelta porque tuvo dos esposas, además de muchas «concubinas». Por otra parte, varios documentos también señalan que Paullu iba frecuentemente a Copacabana, particularmente cuando había conflictos y no sabía qué decisión tomar, se refugiaba nuevamente en esta región donde probablemente recogía consejos; allí también tuvo muchos hijos. Los documentos declaran uniformemente que tuvo muchas mujeres e innumerables hijos naturales ${ }^{6}$.

Pero la razón por la cual el tema de su esposa-mujer es importante es en ralación a su calidad de Inca. ¿Se casaba con su hermana cualquier miembro de una panaca, o este acto

4 Sahuaraura no es una fuente muy confiable; por ejemplo en la genealogía de su antecesor, Paullu dice que éste era hermano de padre y madre de Manco inca (Dumbar Temple, 1937: 117-118).

5 Lo mismo sostiene Sahuaraura.

6 Muerto Paullu en 1549 se suscitó un largo y enojoso litigio entre sus hijos naturales y don Carlos, el hijo legítimo mayor. Aquellos alegaban haber sido legitimados en virtud de la cédula real de 1 de abril de 1544 (Dumbar Temple, 1948: 137, 139-140). 
estaba reservado únicamente para el Inca? Si es así, ¿en qué circunstancias se realizaba el matrimonio? Ellefsen nos da la respuesta: la coronación del nuevo Inca y su matrimonio eran sucesos simultáneos pues tanto el ascenso al trono como el matrimonio eran hechos políticos de máxima importancia (Ellefsen, 1989: 94- 95)7. Entonces, el hecho de que Paullu se casara con su hermana, hacía de él un Inca.

\section{2. ¿UN INCA DEL COLLASUYU?}

Según los Quipucamayos consultados por Vaca de Castro (1542) todas las provincias del Collao y Charcas hasta los Chuis y Chichas servían y respetaban a Paullu y lo habían reconocido

«por Señor de toda la tierra de los Charcas y Collao como a hijo que fue de Huayna Capac Inga, Señor de este reino» (Quipucamayos, in Carillo, 1991 [1542]: 27).

La fuente aclara que en el Collasuyu, luego de la muerte de Huascar, le reconocieron como Señor y le servían como al mismo Huayna Capac. Asimismo cuando entró al Cusco

«fue acompañado de toda la tierra de indios del Collao y Charcas, con muchas muestras de gran valor de su persona y de muchos ingas principales...». (...) «El marqués don Francisco Pizarro con los demás cristianos y capitanes habían tenido noticia que en toda la tierra del Collao y provincias de los Charcas estaba otro inga mucho más Señor que Mango Inga» (Quipucamayos, in Carillo, 1991 [1542]: 27).

¿Cómo entender estas afirmaciones que vienen de una fuente tan temprana y de origen indígena de alto nivel?8. ¿Quizá se refieren a que Paullu fue coronado como Inca de manera paralela a Manco o de manera complementaria? Lo que propone Burga para el caso de Atahuallpa es una posibilidad (Burga, 1988: 61). Sugiere que podría tratarse de un «Ingaranti» según el término de Juan Santa Cruz Pachacuti (también Guaman Poma, llama al Inga ranti «virrey»9), es decir un Inca de uno de los suyus, una «segunda persona» del Inca en palabras de Guaman Poma. Esta habría sido la situación de Atahuallpa mientras Huascar habría tenido el «señorío principal». Estas versiones se corroboran con los textos de Blas Valera y de Guaman Poma quien precisa que «desde Xauxa hasta Quito y Nobo Reyno fue lo de Atahualpa y desde Xauxa hasta Chile, lo de Uascan» (Burga, 1988: 61). «Lo de Paullu», entonces, habría sido el Collasuyu.

Una confirmación de esta hipótesis proviene de fuentes de las provincias del sur. Los mallkus de Charcas dan muestras de su alianza con Paullu declarando en su Memorial que se habían emparentado con él, como buscaban hacerlo con los incas reinantes10. Por su parte los Guarachi de Pacajes ostentan un escudo de armas que en líneas generales es el mismo que el otorgado a Paullu11.

7 El matromonio del nuevo Inca se realizaba con suntuosos ceremoniales donde estaban presentes — como en el de Huayna Capacc - hasta 50000 soldados y multitud de curacas. El de Paullu, sin embargo, dadas las circunstancias tuvo que ser menos ostentoso.

8 Según Wedin la crónica de los Quipucamayos consta de dos partes, la primera dividida en tres secciones, de las cuales la segunda habría sido compuesta hacia 1542 y allí se habla minuciosamente de Paullu, elogiéndolo. Por tanto el texto de los Quipucamayos, se compone en realidad de varios textos donde están compilados varios informes y relaciones (Someda, 2001). Propongo que por lo menos uno de los textos era la versión «oficial» de la historia contada por los quipucamayos de Paullu, como era costumbre entre los Incas.

9 «Y después fue el primero rrey capac apo [el poderosos señor]... y tenía su bizoorrey y segunda persona capac apo Guaman Chaua... yncap rantin [que reemplaza al Inca]...». Figura del Incaptantincapac Apoguamanchaua (1980[1610?]: fig. 340, p. 244), Guaman Poma dice que Capac Apo Guaman Chaua Yarovilca Allauca Guanoco era su abuelo y segunda persona del Inca Topa Inga Yupanqui (1980[1610?]: fig. 340, p. 245).

10 Real Cédula que presentan los caciques Ayaviri probando sus títulos de nobleza, ANB ED. 135, f. 82. Véase Arze \& Medinaceli, 1991: 29.

11 Según la descripción que da Roberto Choque del escudo de armas de Paullu que saca del «Memorial de los méritos y títulos de la familia de Don Josph Fernández Guarache» (Choque, 2003: 6). Si comparamos con el cuadro del escudo de armas de los Guarachi reproducido en Imágnes y presagios de Arze y Medinaceli veremos 
Gutiérrez de Santa Clara, nos abre otra posibilidad. Sostiene que en estos primeros años, y probablemente a la antigua usanza, habría dos Incas que ejercían de manera paralela su reinado. Uno con los españoles y otro en contra de ellos (Gutiérrez de Santa Clara, 1963, Cap. LV: 482; Dumbar Temple, 1939: 226). En este contexto, el matrimonio del Inca Paullu con una hermana suya que se encontraba en el Acllawasi de Coati, al frente de la Isla Titicaca, de acuerdo a la usanza incaica, sería una muestra más de su ascenso como Inca, pues este matrimonio, como vimos, era parte del ritual de coronación del nuevo Inca12.

Nos preguntamos si es posible que en verdad estuvieran actuando dos Incas de manera simultánea en tiempos de conquista. Son conocidas las propuestas de Zuidema en varios trabajos de distintos años y Duviols (1979) sobre la diarquía incaica y la de Pärssinen sobre Incas de los suyus (2003)13, pero no se planteó la posibilidad de que estuviera en vigencia en pleno periodo colonial, aunque fuera un hecho a todas luces visible pues se pensó que el Tawantinsuyu ya no funcionaba. Paullu en el Cusco y Manco en Vilcabamba conformarían, por tanto, una diarquía inca en tiempos coloniales.

\section{LA RELACIÓN ENTRE PAULLU Y MANCO}

Si aceptamos la posibilidad de una diarquía quedan dos aspectos que habría que revisar, el primero es acerca del papel que jugaba cada uno de estos Incas en esta complementación del poder y el segundo se refiere a si en el curso de los acontecimientos se puede observar cómo estaba funcionando.

A comienzos de 1534 Paullu ingresó de manera flamante al Cusco pero no para disputar el trono a Manco (Hemming, 1970: 174). Anteriormente Paullu había sido propuesto por Quisquis a nombre del ejército imperial para ser coronado como Inca pero la propuesta fue desechada por Paullu (Dumbar Temple, 1939: 237) y entró de acuerdo con Manco

«para que obrase a favor de los vasallos y de la tranquilidad del reino y de los intereses de la casa real peruana» (Véase Choque, 2003: 5; sobre la base de Sahuaraura).

Proponemos que este par de autoridades tenían que complementarse en este conflictivo momento, y mientras Manco tenía el rol rebelde, el de la resistencia, Paullu mantenía abierta la posibilidad de negociación, teniendo ambos como horizonte la sobrevivencia de la «casa real peruana». En términos andinos uno sería un Inca auca y el otro yachaj14.

que las figuras internas del escudo son las mismas que las descritas para el escudo de Paullu Inca. Esta similitud ya fue anotada por Teresa Gisbert (2004). Es interesante resaltar que mientras Gisbert toma la descripción del escudo de Rowe, Choque lo hace de la probanza de los Guarachi. Es posible que esta relación se deba a que los Guarachi querían mostrar que eran de «la prosapia de Guayna Capac», como reza el lienzo, pero además de los que colaboraron con los españoles. El escudo de los Guarachi habría sido solicitado después de las rebeliones indígenas y otorgado en 1792.

12 A partir de Pachacutec, el Inca se casaba con sus hermanas y a falta de éstas con sus parientes más cercanas. «Terminadas las ceremonias fúnebres [de Huayna Capac, Huascar] casó con Mama Chuqui Uspai, su hermana carnal ya que al principio Mama Ragua Ocllo se negó a consentir el enlace porque Huascar había dado muestras de crueldad» (Cabello de Valboa, 1951 [1586]: 104 -105). Es decir se casaba con su hermana cuando heredaba el trono.

13 Tom Zuidema en varios trabajos, según Pärssinen desde su temprana obra de 1962 sobre el sistema de ceques en el Cusco hasta trabajos posteriores en 1986; luego Pierre Duviols, 1980. Pärssinen propone tres Incas en correspondencia con el orden de los ceques: «collana, payan y cayao», collana para el chinchaysuyu, payan para el antisuyu y cayao para el collasuyu. El cuntisuyu, por ser el «más pobre», no entraría en este orden. De estos tres Incas, sin embargo solamente gobernaba el de collana-chinchaysuyu, los otros lo reemplazaban eventualmente (Pärssinen, 2003).

14 Como se ve en el caso de Wayna Capac que organizó el valle de Cochabamba y era yachaj y Tupa Yupanqui era el conquistador del valle, según los testigos del litigio de tierras publicado por Wachtel (1981). Un testigo sostiene que Topa Ynga no era yachaj. Wachtel propone que los Incas se percibían como «administradores» o «conquistadores» según los casos. 


\section{RELACIÓN RITUAL DE PAULLU CON EL COLLASUYU}

Por lo dicho anteriormente encontramos a Paullu muy ligado con el ámbito ritual, particularmente del Collasuyu, aspecto que no debe llamar la atención si se tiene en cuenta su relación con el área sagrada de Copacabana y sus islas. Su familia tenía en el Cusco una chacra que era la tercera huaca del segundo ceque del Collasuyu denominada Saucero donde se realizaban rituales y solemnes fiestas en homenaje al Sol

«la cual en tiempo de sembrar iba el mismo rey y la araba un poco. Lo que se cogía de ella era para sacrificios del Sol. El día que el Inca iba a esto era solemne fiesta de todos los Señores del Cuzco. Hacían a este llano grandes sacrificios especialmente de plata, oro y niños» (Polo de Ondegardo, 1990 [1571]: 27).

Por otra parte, cuando regresó de la expedición con Almagro hizo llevar a su morada una de las huacas más importantes del Collasuyu. Se trata de una piedra denominada Huanacauri. El nombre de la huaca hace referencia a uno de los sitios del mito de origen de los incas, donde Ayar Uchu, como mensajero del Sol, se convirtió en piedra. Era uno de los principales adoratorios de todo el reino «y desde entonces se hizo allí la fiesta del Raimi hasta que los cristianos la descubrieron y sacaron de su poder... Poníanlo para la fiesta del Raymi ricamente vestido adornado de muchas plumas encima del dicho cerro de Huanacauri» (Polo de Ondegardo, 1990 [1571]: 31).

\section{ETAPAS DE LA PARTICIPACIÓN DE PAULLU (1535-1549)}

En el curso de la invasión española, Manco se refugia en Vilcabamba después de intentar cercar al Cusco, y Paullu en cambio apoya el ingreso de los españoles. En esta actuación —-donde se ha resaltado su apoyo a la invasión europea- se pueden establecer cuatro etapas que van desde 1535 hasta 1549:

- Primera: participación con Almagro en la expedición por el Collasuyu hasta Chile.

- Segunda: regreso cuando Manco Inca pone un cerco sobre el Cusco.

- Tercera: segunda expedición al Collasuyu con los hermanos Pizarro luego de la muerte de Almagro, expedición que ya no es pacífica.

- Cuarta: desde el regreso con los Pizarro, pasando por su conversión a la religión cristiana hasta su muerte en 1549.

\section{1. Primer momento: el ingreso al Collasuyu de Paullu con Almagro}

Una de las primeras situaciones en que aparece Paullu en los documentos cuzqueños es en una famosa ocasión cuando Manco se quejó ante un grupo de parientes suyos y ante Pizarro sobre aquellos que osaran hablarle directamente y sin respeto. El portavoz de Manco Inca fue Paullu que reprendió a los nobles diciéndoles que

«iPor qué vosotros os atreveis a hablar al Inga vuestro señor tan libremente y le decís lo que queréis con favor de los cristianos? Os podéis poner de rodillas delante de él y pedirle perdón de tan gran atrevimiento...».

La reacción de Pizarro fue dar una bofetada a Paullu con lo que terminó la reunión. Se observa, pues, una relación conjunta aunque, como correspondía, subordinada de Paullu respecto a Manco.

Se observa una situación idéntica cuando Manco Inca, apenas coronado, salió del Cusco con Hernando de Soto y dejó a Paullu en el Cusco en su lugar (Hemming, 1970: 174), así como Huayna Capac había dejado por gobernador a su tío Guaman Achachi antes de salir a la guerra contra los quitos. 
Posteriormente, a mediados de 1535, Almagro preparaba la expedición por el Collao hacia Chile, Manco Inca y sus asesores decidieron que Paullu y el sumo sacerdote Vilac Umu irían con Almagro por el Collasuyu. Hay varias teorías sobre los intereses que cada bando puso en este viaje, pero lo que ahora nos interesa es rescatar la posibilidad que entre Manco y Paullu hubiera algún acuerdo para deshacerse de Almagro y colaborar todos en el futuro alzamiento que culminaría con el cerco a la ciudad del Cusco15.

Cuando la enorme comitiva, de 500 españoles, 100 esclavos negros y miles de indígenas llegó a Tupiza después de una larguísima travesía16, el sacerdote Vilac Umu abandonó a Almagro y ocultamente regresó al Cusco para organizar el alzamiento con Manco Inca. Pero Paullu no retornó con él. Muchos autores han interpretado esto como una colaboración de Paullu hacia Almagro, lo cual se confirmaría porque no solo entonces sino antes y después le siguió brindando su apoyo.

Pero es posible entender la situación desde otro punto de vista. La colaboración de Paullu durante su paso por el altiplano parecía tener la intención de alejarle lo más posible, algo así como si se abriera un océano de gente que lo dejaba pasar para luego cerrarse. Esto ocurrió así, puesto que cuando el colaborador de Almagro, Orgoñez, iba al encuentro de este, alrededor de julio de 1536, los indígenas comenzaron ya a alzarse. Esta resistencia tuvo un carácter más organizado durante el ingreso de los Pizarro en 1538.

El plan entonces, sería matar a Almagro y su gente cuando estuvieran en Chile. De hecho, mientras el mayordomo de Almagro llegaba a Copiapó con la cédula Real que le confirmaba su territorio, otros mensajeros de Manco llegaban para avisar a Paullu que todos los preparativos para el cerco a la ciudad del Cusco estaban en curso y que él debía matar a Almagro. Pero Paullu no lo hizo así. En cambio, ayudó a Almagro a volver al Cusco atravesando el desierto de Atacama. Luego explicó que le resultaba imposible porque se le habían muerto 10000 indios al pasar la cordillera y no se animó a tomar una decisión tan arriesgada (Choque sobre la base de Garcilaso) ${ }^{17}$. De todas maneras en Copiapó hubo una crisis y 8000 indios abandonaron la comitiva ante la crueldad de Almagro18.

Manco Inca estaba furioso y mandó a matar a Chalco Yupanqui, el gobernador del Collasuyu que desde Copacabana acompañaba a Almagro y a Paullu. Pero no hizo nada contra Paullu. Almagro, por su parte, a partir de Tupiza puso guardias a Paullu porque no confiaba en él y esta fue una actitud constante de los españoles ${ }^{19}$.

Dice Oviedo que cuando volvían de Chile, desde el valle de Tacna, Almagro envió indios mensajeros a Manco y Paullu

15 Francisco López de Gómara (Historia General de las Indias) declara que Manco «concertó con su hermano Paullu» con Villac Umu y con Felipillo el asesinato de Almagro y los españoles en las Charcas (Dumbar Temple, 1939: 208).

16 Pedro Mariño de Lovera en Historia de Chile desde el descubrimiento... dice que Paullu traía un contingente de 60000 indios (Dumbar Temple, 1939: 210). Aunque exagere, da la idea de que era enorme. Por su parte, el abate Ignacio de Molina (Compendio de la Historia Civil del Reino de chile. en Col de Historiadores de Chile... Tomo XXVI) relata que Almagro salió del Cusco a fines de 1535 con 570 españoles y 15000 indios y eligió el camino de la sierra (Dumbar Temple, 1939: 212).

17 José Pérez García (1900), a pesar de hacer un relato detallado del viaje de Almagro, no habla de Paullu pero dice que cuando trajeron a Almagro a los despachos de la gobernación de Nueva Toledo, los indios que vinieron dieron aviso a los suyos de que degollasen a Almagro, pero que no atreviéndose y se limitaron a desampararlo (Dumbar Temple, 1939: 213), huyendo en gran cantidad. Montesinos también dice que «el mensajero que fue a Chile a avisar a Paullu Inga que matase a Almagro y a sus compañeros llegó tarde ya que don Diego de Almagro había salido de Chile y venía en Atacama» (Temple, 1939: 208).

18 Almagro ejercitó una severa venganza contra los indios que habían matado a tres españoles y solo perdonó a un noble por intercesión de Paullu «... ruegos de Paullu al estar con él algo desabrido porque en el valle de Copiapó se le habían huido una noche sin ser sentidos ocho mil indios» según el mismo Mariño Lovera en Historia de Chile (Dumbar Temple, 1939: 211).

19 Según el testigo Martín Gueldo de la probanza, aunque en el regreso de Chile «muchos castellanos hablaban mal de este Inca» (Dumbar Temple, 1940: 53), lo cual muestra que no terminaban de confiar en él. 
Paullu y Manco zuna diarquía inca en tiempos de conquista?

«hizo lo mesmo por su parte, a lo menos en presencia de los christianos. Y aunque de nuevo el general le tornó a preguntar lo que sabía, siempre vaciló e avisó a los otros indios para que se le encubriesse...».

Posteriormente, en Arequipa, cuenta Oviedo que los indios estaban «cautelosamente pacíficos» y discutían entre ellos y Almagro se dio cuenta que la causa era Paullu y que él sabía lo que pasaba y no le habían avisado (aunque en Chile se supo del levantamiento de Manco, según el propio Oviedo)

«púsole temor para que se lo declarase, diciéndole que le haría quemar si le mintiese en cosa alguna... y púsole públicas guardas para que supiese que no podía huir» y Paullu «informado de lo que él sabía le dio al Adelantado alarmantes y exageradísimas noticias de la sublevación de Manco» (Oviedo en Dumbar Temple, 1939: 206).

Cuenta además que cuando el cerco sobre el Cusco estaba en marcha, los españoles estaban al corriente de su deslealtad, aunque lo disimulaban por conveniencia (Oviedo in Dumbar Temple, 1939: 206). Según Temple, Almagro tenía conocimiento del concierto entre Paullu y Manco ya que incluso le mandó una carta a Manco donde decía:

«A Paulo, vuestro hermano, tengo conmigo e le amo como a mi hijo y él os quiere mucho y en todo os es buen hermano» (Dumbar Temple, 1939: 206).

Es evidente, entonces, que la actuación de Paullu, a pesar del juicio histórico posterior, por lo menos durante el viaje a Chile, aunque estaba a favor de los españoles, dejaba siempre dudas en cuanto a su posición. Creemos que la actitud de Paullu estaba dictada por su situación como alta autoridad incaica que tenía la misión de mantener abiertas opciones de paz para la élite inca $y$, por ende, para el destino del imperio incaico20.

Creemos que su cálculo iba por mantener las dos opciones abiertas, una rebelde y la otra de paz. Por eso Manco nunca mandó a matar a Paullu, aunque pudo hacerlo muy fácilmente como hizo con otros. Paullu intervino en su contra sólo en situaciones extremas y sólo hasta cierto grado, de tal modo que la resistencia en Vilcabamba se mantuvo todavía por mucho tiempo. Fracasaron tanto los intentos de levantamiento de Manco como los de Paullu por venir en son de paz.

De todas maneras en la actitud de Paullu se ve que entendió muy pronto cuál era la nueva fuente de legitimidad, es decir los españoles, como dice Lamana (1996) y se percibe, tras las opiniones que dan de él y de sus actos, que se trataba de una persona con «gran influencia entre los indios, con dotes de estratega y su oportuno dominio de las circunstancias cualidades que le fueron reconocidas unánimemente y por las cuales fue elogiado en todas las crónicas y relaciones que tratan de la expedición a Chile» (Dumbar Temple, 1939).

\section{2. Segundo momento: regreso de Chile y el cerco a la ciudad del Cusco}

Cuando regresaron al Cusco, Almagro dio a Paullu el palacio de Colcampata que había sido de Huáscar y allí fijó su residencia. Mientras tanto Almagro trató nuevamente de atraer a Manco quien se había retirado a Tambo. Sin embargo se decía que Paullu «en secreto le enviaba a decir que le querían engañar para quemarle». La opinión de la época era que hacía esto «porque no viniendo el Inga él era señor» (relación del Sitio del Cusco in Dumbar Temple, 1939: 217). Como

20 Según Dumbar Temple, en esta etapa se desprende el acuerdo que hubo entre Paullu, Manco y el sumo sacerdote para asesinar a los españoles en Chile. De los mismos testimonios se desprende que Paullu no huyó de Chile sino que logró convencer al Vilac Umu sobre la imposibilidad de su realización y Paullu se habría quedado con Almagro para evitar sospechas. Dumbar Temple cree que Paullu no rompió con Manco sino después de haber sido designado Inca por el Adelantado. Desde mi punto de vista, Dumbar Temple tiene razón en la primera parte, pero luego cae nuevamente en una lógica del interés individual que creo no entraba exactamente en la mentalidad indígena de la época. Por otra parte no es tan cierto que tomó las armas contra Manco. Fue mucho después con los Pizarro que entró con ellos, pero aún allí su participación fue, como siempre, poco clara. 
Almagro no consiguió atraer a Manco que había sido antiguamente su aliado, primero coronó a Paullu como Inca y luego decidió atacar a Manco en su fortaleza en la selva. En este ataque no participó Paullu.

La coronación de Paullu, entonces, es uno de los acontecimientos más importantes de esta coyuntura. Aunque existen algunas dudas sobre el momento exacto de este hecho, parece que no fue inmediatamente después de su regreso de Chile sino después del triunfo de Almagro contra Alvarado en el puente de Abancay, en julio de 1537, según Hemming21. Después de esta jornada lo habrían coronado como Inca, «por leal a los españoles, pero no por sucesión de sangre, pues vivía Manco» dice Calancha (Dumbar Temple, 1939: 223).

En esta etapa Paullu tenía una verdadera corte de indios en el Cusco. Además se puso decididamente con Almagro y contra Pizarro (Dumbar Temple, 1939: 219).

La desconfianza hacia Paullu se debía en parte a que los españoles no querían dejar resquicios que dejaran duda de la superioridad europea y criticaban a Almagro que industrió a Paullu sobre la manera de herir y matar a los cristianos (Dumbar Temple, 1939: 221-222). Cuando Paullu mandó matar a un español de nombre Castañeta por orden de Almagro, este no se dejó atrapar

«pareciéndole afrenta dejarse atar de indios» le cortaron la cabeza... [esto]a los españoles les pareció pésimo que un español muriese en manos de indios por orden de otro español porque se dio introducción y atrevimiento a los indios que matasen los cristianos» (Dumbar Temple, 1939: 221-222).

\section{2. 1. Sale Almagro contra Manco}

Otro acontecimiento importante en esta etapa para entender la relación Manco-Paullu es el ataque que organizó Almagro contra Manco Inca a mediados de 153722. Para Almagro seguía siendo un problema la actitud belicosa de Manco. Como no pudo atraerlo, resolvió hacerlo por la fuerza enviando a Ordóñez 200 ó 500 castellanos para atacarlo (según Molina u Oviedo). En estos acontecimientos hubo cruce de mensajes entre los dos Incas. Se conoce que Manco envió mensajeros a Paullu para que «se juntase con ellos» y Herrera dice que Paullu «estaba muy hallado con los españoles y gustaba de sus costumbres», no lo aceptó y su respuesta ha sido en cierto modo dejada de lado. Paullu le dijo a su hermano que

«se acordase que con tener sobre el Cusco doscientos mil hombres, el poco fruto que había hecho contra doscientos que se lo defendieron, perdiendo cincuenta mil en aquella guerra, dejando muchas viudas y huérfanos y por lo tanto le rogaba que se pacificase con el Adelantado que aunque le había dado la borla y declarado por Inga en aquel Imperio, como hijo de Guainacaba como lo era, él de buena gana renunciaría la dignidad porque él con ella viviese quieta y pacíficamente» (Herrera in Dumbar Temple, 1939: 230-231).

Cuales quieran que hayan sido los argumentos, ambos Incas se mantenían en su posición. Manco seguía rebelde en la selva apoyado por el sacerdote Vilac Umu y Paullu en el Cusco recibiendo honores de los españoles. Él no participó del ataque a Manco y estando en el Cusco recibió de regalo un sol de oro que le había sido arrebatado por Orgóñez a Manco Inca23.

21 Dumbar Temple cree que se efectuó en el último momento porque antes aún Almagro no había roto decididamente con Pizarro, quien no intervino en la coronación de Paullu; además se hallaba todavía en buenas relaciones con Manco Inca tratando de atraerlo. Le entregó la borla imperial solo después que los Pizarro estuvieron en prisión y cuando entró al Cusco y después de la derrota de Alvarado por Almagro, viendo que Manco persistía y reconociendo el apoyo de Paullu (Dumbar Temple, 1939: 218).

22 Según Hemming (1970: 232) Orgoñez regresó de su ingreso a Vilcabamba a fines de julio de 1537.

23 «Oviedo cita la expedición de Orgóñez contra el Inca en capítulos diversos, cita que Orgoñez sorprendió al Inca y lo obligó a huir en compañía de Vilac Umu hasta unas sierras donde no lo pudieron hallar, agregando que los españoles lograron liberar a cuatro españoles que tenía preso el Inca. Además dice que tomaron como botín el sol 
Sin embargo, Paullu jugaba otra vez un doble papel azuzando a Almagro contra Pizarro diciéndole que si vencía a Hernando Pizarro, Manco le vendría en paz «que así lo había enviado a decir con unos orejones» (Oviedo en Dumbar Temple, 1939: 242)24, pero ya estaba observando que eventualmente tendría que apoyar a Pizarro25. Tanto así que después de la derrota de Almagro en las Salinas, Paullu huyó con muchos españoles, y allí esperó la propuesta de paz de Hernando Pizarro, sabiendo que su ayuda para los españoles era indispensable. Según Lamana, Paullu cambiaba según lo hacían las erráticas posibilidades de legitimidad 26.

\section{3. Tercer momento: el ingreso violento al Collasuyu: Paullu con los Pizarro}

Aunque en la práctica la resistencia organizada por Manco Inca desde la selva peruana no se detuvo, se puede distinguir una etapa diferente a partir de la muerte de Almagro, cuando los Pizarro toman el control de todo el territorio. Esta coyuntura coincide con el ingreso de los Pizarro al Collao. Es aquí donde se trasladará el centro de la resistencia, en lo que se ha denominado «la Segunda Rebelión» (Hemming, 1970).

En 1538, luego de la muerte de Almagro y cuando los Pizarro tenían el dominio total, la perspectiva histórica de indios y europeos era completamente distinta. Una vez derrotado Almagro, Pizarro —que desde 1537 ostentaba el título de Marqués (Arze Quiroga, 1969: 178)— no tenía oponente en la América del Sur, excepto el Adelantado Pedro de Mendoza en el lejano Río De la Plata27. Esto se evidencia por los avances europeos en todas las direcciones del continente: por el Río de la Plata y río Paraguay ingresaba el seguidor de Pedro de Mendoza, Juan de Ayolas, donde luego entraría Peranzures enviado por Pizarro. Hacia Charcas marcharon los Pizarro y a Chile, aunque un poco más tarde, ingresó a Valdivia. El propio Francisco Pizarro, una vez que no estaba Almagro estorbándole, envió al Norte a Belalcázar a disputar la conquista de Nueva Granada. Gonzalo Pizarro, luego de Charcas, fue enviado «al país de la canela» hacia donde luego iría Orellana en una audaz travesía (Arze Quiroga, 1969: 178-179). Es decir, que es evidente la absoluta seguridad de los conquistadores de su dominio en el nuevo territorio. En cambio los indígenas, comandados por los incas, en un último esfuerzo resistían esta invasión que se venía por todos los frentes.

El Collasuyu, entonces significaba uno de los últimos reductos de resistencia indígena. A la diferencia de lo que pasó cuando entró Almagro, cuando lo hicieron los Pizarro, el territorio del Collasuyu

que es el que esos indios tienen por dios y Orgóñez le dio a Paulo por tenerlo contento. Orgoñez regresó al Cusco por llamado de Almagro» (Dumbar Temple, 1939: 235).

${ }^{24}$ Cuando se desencadenó la lucha entre Pizarro y Almagro, Paullu estaba del lado de Almagro y lo acompañó hasta el valle de Chicha permitiendo que la gente saliera en paz y le proporcionó espías quienes le avisaban de lo que pasaba en el campo de Pizarro. Se dio el enfrentamiento en Guaitará a pesar que los almagristas se burlaban de la temeridad de Pizarro; éste intentó tomar el paso de Guaitará; otros dicen que se prepararon para el enfrentamiento. Hernando Pizarro acometió con 300 hombres e hizo huir a los almagristas, entre ellos Paullu. Pero luego se ofreció para ir solo contra Pizarro en vista de que Almagro estaba muy enfermo; sin embargo Almagro nunca consintió. Se preguntó a Almagro porque no dejaba ir a Paullu, y este dijo que no quería que los indios supiesen que eran bastantes para desbaratar a mil cristianos. Pero quizás era por la desconfianza que le tenía a Paullu (Dumbar Temple, 1939: 237-240).

${ }^{25}$ La adhesión de Paullu hacia Almagro flaqueaba desde la derrota de Guaytará; viendo el desconcierto en el campo del Adelantado y el continuo desbande de tropas se concertó con Villegas para pasarse al bando de Hernando Pizarro, pues comprendió las pocas probabilidades de triunfo que tenía el Adelantado... para lo cual era mejor huir antes de la batalla (parece que intentó huir). La impunidad más completa siguió a esta acción desleal de Paullu, quien, imposibilitado de huir, se vio obligado a intervenir en la batalla final (Dumbar Temple, 1939: 243).

26 «En medio del mar de contradicciones que el mundo español presentaba, los nobles cuzqueños se movían sin saber exáctamente a dónde ir. De tal manera la actuación de Paullu no debe ser evaluada en términos concretos de su errática alianza militar, sino como oscilación de una forma de reconocimiento a otra» (Lamana, 1996: 96).

27 En esta parte seguimos la tesis del historiador Eduardo Arze Quiroga que sostiene la entrada simultánea por el altiplano y el Río de la Plata buscando controlar la región de Charcas (1969: 177 ss.) 
estaba todo levantado. Se encontraba en pie de guerra aunque también reavivando antiguas rivalidades de las provincias del Tawantinsuyu 28.

El encargado de organizar la resistencia en el Collasuyu de parte de los incas fue el general Tisoc (Murúa, 1962: 240) que tenía la misión de levantar a las provincias del Collasuyu y organizar al ejército Inca en Pocona al SE de Cochabamba. Tisoc, tío de Manco Inca, era una autoridad incaica que había trabajado coordinadamente con su sobrino en muchos momentos decisivos de este periodo. Pero también parece que los pacajes, al sur del Titicaca, habían tomado la iniciativa de una resistencia independiente de las órdenes incas, comandados por Quintiraura.

La resistencia en el Collasuyu tuvo lugar particularmente en tres enfrentamientos. El primero en el río Desaguadero con la resistencia a cargo de los lupacas y los pacajes donde fueron derrotados y fue ejecutado Quintiraura, cacique pacaje encargado de liderizar la revuelta. Apoyando a los españoles, aunque no de manera decisiva, estaban los collas, que se dice lo hicieron a instancias de Paullu que tenía relación con ellos gracias a sus vínculos con Copacabana. Luego del Desaguadero, la resistencia se trasladó a los caminos mucho más al sur. Primero en Paria y luego se concentra en un cerco que los indios pusieron a Gonzalo Pizarro y a su gente en Cochabamba, donde actuaron coordinadamente los antiguos «guerreros de Inca» de la Confederación Charca (charcas, caracaras, chuis y chichas) juntamente con los de la Confederación Quillaca de Oruro (carangas, quillacas y soras además de los mitmas de Pocona). El tercer enfrentamiento tuvo lugar en Pocona entre la gente de Gonzalo Pizarro y los restos del ejército incaico y particularmente contra los indios chichas que estaban bajo el mando de Tiorinaceo.

En todos los lugares Paullu tuvo una actuación importante, particularmente como estratega o como enviado de los españoles para conseguir la rendición de los jefes étnicos. En el Desaguadero, ante una feroz resistencia, fue Paullu el que propuso construir enormes balsas que permitieron pasar los caballos y los hombres con pesadas armas. En Cochabamba, a diferencia de otros lugares, estuvo luchando abiertamente incluso obligando a su gente a no huir hiriendo a algunos de los de su bando. En Pocona, tuvo el decisivo rol de convencer nada menos que al general incaico Tisoc de que era hora de «venir en paz» y lo consiguió. Asimismo fue el inicio de una cadena de sumisiones de los señores étnicos que optaron por dar «obediencia a su Majestad».

A esta altura Paullu parece que estaba convencido que no era posible resistir. Las cifras de los muertos de uno y otro bando bastarían como argumento para esto. En Cochabamba, frente a 4 españoles se habla de entre 800 y 8000 indígenas muertos. El cerco a la ciudad del Cusco no pudo llevarse a cabo con 200000 sitiadores en palabras de Paullu, frente a algo más de 200 europeos. En el ingreso hacia Chile en la comitiva de Almagro, las pérdidas españolas fueron mínimas frente a miles de muertos indígenas por los malos tratos, el frío y la dureza de la jornada29. Sobre las causas de la derrota indígena se ha argumentado mucho pero desde la perspectiva de Paullu parece ser que se interioriza una mezcla de fatalismo histórico — no había otra posibilidad que aceptar la presencia europea io había otra? - con una constatación de superioridad bélica, dada por las armas y, sobre todo, los caballos. No es una casualidad que en la selva, donde resistía Manco Inca, estas armas no tuvieron el mismo efecto y la resistencia duró casi 40 años.

Paullu, entonces, era el portavoz de la política de aceptación de los europeos en las mejores condiciones posibles. $Y$ esta fue la actitud que luego adoptaron todos los señores étnicos del Collasuyu. Pero no era sino una cara de la medalla, la otra era la rebelde que seguía en Vilcabamba con Manco.

El curso del ingreso de los Pizarro al Collasuyu que duró seis meses, comenzó con los enfrentamientos y se fue convirtiendo en todo lo contrario. Bajo el mando de Tisoc y con la colaboración de los señores de los charcas, caracaras y luego quillacas, los Pizarro recibieron

${ }^{28}$ Muchos cronistas coinciden en que el altiplano estaba sublevado y que los Pizarro tuvieron que «apaciguar y conquistar» el Collasuyu (Pizarro, Quipucamayos, Cieza, [1989], Oviedo).

29 Nos llama la atención que, hasta donde tenemos conocimiento, en ninguno de los documentos revisados se hable de alguna epidemia. 
la información de las riquezas locales que estaban bajo el dominio Inca. De este modo les «descubrieron» las minas de oro, plata y estaño de la región que habían sido tapadas para que no atrajeran más la codicia europea. Le señalaron particularmente la mina de Porco y la veta que era del Inca fue adjudicada a la Corona. Esta expedición concluyó a fines de marzo de 1539.

\section{4. Cuarto momento: retorno al Cusco con los Pizarro y total aculturación}

Una vez terminada la jornada al Collasuyu, el 2 de abril de 1539, Gonzalo y Paullu regresaron al Cusco mientras Hernando Pizarro era enviado a España a rendir cuentas por la muerte de Almagro. Como Manco Inca seguía siendo un problema para los españoles, Francisco Pizarro decide enviar a su hermano Gonzalo contra Manco. Gonzalo, entonces organiza un fuerte ejército para atacar a Manco; en esta ocasión sí participó Paullu (según Pedro Pizarro y Herrera).

Entiendo que es la primera vez que Paullu actuaría en contra de su hermano Manco. Los Pizarro eran mucho más audaces que Almagro que guardaba en cierta manera las apariencias de respeto al Inca. Según la versión de los Quipucamayos, Manco se iba internando cada vez más en la selva con más de 60000 indios de guerra. Los españoles tuvieron que dejar los caballos e ingresar por las laderas de la montaña uno detrás de otro. En cierto lugar sufrieron una emboscada con una lluvia de piedras despeñadas. Allí, el gran contingente se dividió en dos pensando que todo el primer grupo había muerto. Paullu iba atrás y fue a instancias suyas que esperaron ver qué había sucedido, en contra de lo que varios españoles opinaban. Algunos españoles creían que la propuesta de Paullu era una treta y se opusieron a esperar a lo que Paullu habría respondido (según la versión de los Quipucamayos):

«Admirado estoy señores que tan poco concepto tengan de mi con haber visto lo que yo he hecho y hago en favor de los xtianos. Hagosle saber que lo que fuere de los xtianos será de mi, porque después que los xtianos entraron en este reino, les he servido con mucho amor y lealtad, siendo siempre contra los míos, por tener entendido ser lo más acertado servir a Dios, e para más seguridad de vosotros, échenme luego una cadena y prisiones y tenganme en guarda hasta que sepamos enteramente de los demás xtianos que faltan y cuando sintieren que en mi hay doblez, vengan o matenme luego como a tal traidor, porque en este negocio y trance tanto va por mi como por cada uno de vosotros».

Pizarro, igual que Almagro en Chile, le puso guardias sin que él lo supiera. Llama la atención en este discurso la idea reiterada que Paullu entendía que su destino estaba unido al de los cristianos. Enviando mensajeros encontraron solamente 36 españoles muertos; luego llegaron noticias que en una llanada se encontraban vivos los otros 200. Manco, por su parte continuó internándose en la selva escapando dos veces de ser capturado por Gonzalo Pizarro.

En esta ocasión tampoco pudieron atrapar a Manco aunque tomaron presa a su hermana-esposa que luego sería sacrificada en represalia por la altivez de Manco ante la búsqueda europea de atraerlo a su bando. Sin embargo, tampoco los de Manco mataron a Paullu que iba en la retaguardia de la comitiva a pesar que, según la relación de Tito Cusi, Manco apresó y mandó matar a dos de sus hermanos, Inguill y Uaypa, que iban con Paullu (Tito Cusi, 1991 [1570]: 80).

La Declaración de Quipucamayos cuenta que Paullu logró que gente de Manco se pase a su bando pacificando la tierra y dejando a Manco con 3000 y no 60000 indios (Dumbar Temple, 1940: 42-43). De todas maneras otras fuentes dan a entender que Paullu y Manco nunca perdieron contacto y se mantenían informados de lo que hacía cada cual. Según Dumbar Temple se trataba de intrigas para que Manco no llegue a acuerdos con los españoles. Sin embargo, aún 25 años después de la muerte de Paullu ocurrida en 1549, sin estas supuestas intrigas la versión rebelde de la conquista seguía resistiendo30.

30 De la probanza de Paullu se deduce que mientras Francisco Pizarro estaba en Yucay tratando de hacer las paces con Manco, Paullu intervino probablemente para destruir estas tentativas. El testigo Alonso de Toro dijo que «oyó decir a los mensajeros de Mango Inga... cómo el dicho Pablo enviaba mensajeros y otros avisos» (Dumbar Temple, 1940: 44). 
Después de este ingreso fallido contra Manco, Paullu regresó al Cusco siendo ya parte del proceso colonial. Los hechos más significativos en esta fase se refieren a la consolidación de su papel como autoridad indígena sometida al poder español. En primer lugar el reconocimiento español de ciertos privilegios por lo que se le otorgaron tierras y yanaconas en las zonas más ricas: en Hatuncana, en el valle de Jaquijaguana, algunas en el Antisuyu en tierras que habían sido de Huayna Capac y también en otras que habían sido suyas como las de Copacabana31. Estas encomiendas se le habrían dado como recompensa porque él los ayudaba «contra sus propios hermanos y parientes» (testamento de Mancio Sierra, véase Dumbar Temple, 1940: 47).

\section{TRANSFORMACIÓN RELIGIOSA}

La posición de Paullu fue variando con el transcurso del tiempo. Parece que fue asimilando la invasión como algo irreversible y trató de ubicar - a él, a la élite inca y a la sociedad indígenaen un lugar de respeto y consideración, del mismo modo como habían hecho los incas con los pueblos conquistados. Esta situación de vencido implicaba también una transformación en su manera de ver el mundo, y por supuesto, una transformación religiosa que tuvo que ser paulatina y difícil. Fue tal vez uno de los hechos de mayor atención en su momento.

Nuevamente, esta aparece como la principal fuente de legitimidad, el bautizo de Paullu era una muestra de aceptación de parte del nuevo poder reinante.

«La iglesia era un medio más para legitimar su poder frente a la Corona y quedar bien con Dios y con el Rey» (Lamana, 1996: 88).

Cuando Paullu elabora su información en abril de 1540 ya declara su intención de volverse cristiano (Dumbar Temple, 1940: 49). Para entonces Francisco Pizarro había sido asesinado y en este conflictivo momento, ni crónicas ni relaciones de la época mencionan a Paullu que, al parecer, se mantuvo a la expectativa. Según Dumbar Temple, la actitud de Paullu sería la que adoptaba en todos aquellos periodos en que la lucha entre bandos no acusaba un vencedor; paciente esperaba en el Cusco o huía a su refugio en Copacabana (Dumbar Temple, 1940: 54).

Hacia 1541 Paullu se estaba preparando para su bautizo. Para entonces ya estaba en el Cusco el Lic. Vaca de Castro, enviado por la Corona propiciando el bautizo del Inca quien tomará su nombre, Cristóbal. Esta decisión tuvo que implicar un difícil proceso de cambio.

«abandonando las idolatrías de sus mayores dando por ello [permiso] al provisor para que los enterrase los cuerpos de su padre Guaina Cava con otros tíos primos, etc. a pesar del llanto de su madre y parientes» 32 .

Su bautizo fue una ocasión memorable que tuvo lugar en 1543. Fue bautizado, según varios documentos, junto con su mujer, madre y hermana además de varios incas 33 . Hubo incluso rumores de que Manco había salido de incógnito a presenciar el acontecimiento. El padrino de Paullu fue Garcilaso de la Vega, el padre del cronista (Garcilaso, 1986 [1606]).

Un dato interesantísimo que sale a raíz de su bautizo es el que da Herrera indicando que después de este acontecimiento, los criados de Vaca de Castro se hicieron ermitaños predicando

31 Recibe encomiendas y reconocimiento de sus tierras en Copacabana el 22 de enero de 1539. Antes de la jornada de Gonzalo Pizarro y Paullu contra Manco le había dado la encomienda de Hatun Cana, una de las más ricas del Cusco. (...) Paullu tenía además tierras en Copacabana y en Episcara en el valle de Jaquijaguana (Dumbar Temple, 1940: 47)

32 Según una carta de Vaca de Castro al Emperador Carlos V fechada en nov. 1542 (Dumbar Temple, 1940: 58-59).

33 Fue bautizado por el comendador Fray Juan Pérez de Arriscado clérigo presbítero, cura y vicario de la Santa Iglesia del Cusco poniéndole como nombre Cristóbal; también fueron bautizadas su mujer Mama Usica como Catalina, su madre como Juana Añas Collque y su hermana como Beatriz Huayllas Ñusta. En una antigua genealogía aparecen en el bautizo varios incas parientes incluso de Manco (Dumbar Temple, 1940: 57). 
por el Collao la doctrina a los indios 34 dando, a nuestro entender, insumos al mito de Santo Tomás ligado a Tunupa.

Paullu a su vez, por ser el primer Inca cristiano, hizo construir una capilla en honor a San Cristóbal. Dicen los Quipucamayos que con el tiempo fue la capilla de los indios del Cusco y allí se bautizó el nieto de Paullu don Melchor Carlos cuyo padrino fue el virrey Toledo. Habían tendido un puente casi imposible entre dos mundos, en un periodo de muchísima violencia.

Al año siguiente del bautizo de Paullu, en 1544 muere Manco Inca en Vilcabamba. A raíz de esto nuevamente salen a la luz datos que muestran que ambos Incas estaban informados uno del otro. Ese mismo año el rey legitimó a los numerosos hijos naturales de Paullu Inca (según Calancha) y, en 1545, le otorgaron un escudo de armas (Dumbar Temple, 1940: 65).

Algunos años más tarde, en 1548 La Gasca encomendó a Paullu la misión de ayudar a los españoles en sus negociaciones con Sayri Tupac, el hijo de Manco Inca para que abandonara Vilcabamba (Dumbar Temple, 1940: 71). En 1549 cumpliendo la solicitud de La Gasca, entrado el verano, Paullu salió del Cusco al pueblo de Guaynacapaco y de allí despachó mensajeros a Vilcabamba, pero enfermó tan gravemente que tuvo que regresar al Cusco donde murió a los pocos días.

Poco antes de morir se casó con su mujer doña Catalina Tocto Sisa cuando su hijo Carlos tenía 8 años. A su muerte se hicieron sentidas ceremonias a la usanza antigua. Molina el Almagrista dice «el día de su muerte... como supieron todos que había expirado, todos los indios de guerra vecinos al Cusco con todas sus armas de flechas y lanzas y porras... se subieron a la casa del dicho Inga Paulo y la cercaron toda de todos los altos y paredes... dando grandes voces y grita allende que todos los moradores del Cusco lloraban a voz en grito. (...) y allí estuvieron guardando la casa de Paullu hasta que lo enterraron... serían hasta 400 o $500 \ldots$ dijeron que era costumbre cuando moría señor natural porque con la alteración de la novedad no se metiese algún tirano en la casa del señor y se enseñorease de la mujer e hijos y los matase...» (Dumbar Temple, 1940: 76).

Mientras tanto los indios le hicieron

«una estatua pequeña y le pusieron algunas uñas y cabellos que secretamente le quitaron, la cual estatua se halló tan venerada dellos cuanto cualquiera de los otros cuerpos de los reyes Incas» (Cobo en Dumbar Temple, 1940: 76).

Algunos años más tarde, después de su muerte, la tradición oral recuerda que las uñas y cabellos de Paullu se colocaron en la imagen de San Cristóbal que se encontraba en esta capilla (Teresa Gisbert, comunicación personal).

\section{COROLARIO}

En Copacabana, lugar de formación y refugio de Paullu, antes y después de la invasión europea, el cronista Ramos Gavilán refiere que

«Este don Christoval Topa Inga es el mismo a quien por otro nombre (antes de ser baptizado) llamavan los Indios Paullo Topa Inga... tuvo muchos hijos assi en el Cusco, como en Copacabana, fue padre de Don Carlos Inga y abuelo de Don Melchior Inga, el que murió en España. Este Paullo Topa, tuvo un hijo en Copacabana, entre todos más señalado, que fue Don Francisco Tito...» (Ramos Gavilán, 1988 [1621]: 189)35.

34 ... «primeramente puso mucha diligencia en la conversión de los indios y por sus amonestaciones se bautizó el Inga Paullu... y se llamó Chirstoval como Vaca de Castro y unos hombres, sus criados se hicieron religiosos y a manera de hermitaños andaban por el Collao enseñando la Doctrina Christiana a los indios» (Dumbar Temple, 1940: 58).

35 La misma referencia de Ramos Gavilán presentó Roberto Choque en su ponencia presentada al Congreso de Americanistas en Santiago de Chile, 2004. 
Recordemos que don Francisco Tito Yupanqui fue el escultor que realizó la imagen de la Virgen de Copacabana. ¿Podemos confirmar este dato?

Es preciso subrayar que se considera a Ramos Gavilán un cronista confiable que conoció personalmente a la familia inmediata del escultor, tanto así que transcribe una autobiografía de Francisco Tito «que dejó hecha de su propia mano» que le fue otorgada al cronista por un hermano de éste (Ramos Gavilán, 1988 [1621): 234). Por otra, sabemos que Paullu se casó con una aclla en Copacabana, sabemos también que tuvo muchos hijos en este lugar.

Los datos biográficos de Tito Yupanqui parecen confirmar la afirmación de Ramos Gavilán. Según los esposos Mesa Gisbert (1972) la primera obra de Tito Yupanqui que se conoce es de 1579 cuando tendría entre 20 y 30 años, por lo que se puede suponer que nació entre 1540 y 1550 , es decir mientras Paullu Inca estaba vivo (recordemos que murió en 1549), lo cual coincide con la afirmación de Ramos Gavilán.

A través de su hijo, Paullu, parece buscar su reivindicación a través de la milagrosa imagen de la Virgen más venerada en Bolivia.

\section{A MANERA DE CONCLUSIÓN}

La figura de Paullu nos permite conocer mejor una parte del difícil y tortuoso proceso de conquista. En este marco, nuestra propuesta de funcionamiento de una posible diarquía no es una proposición cerrada sobre todo porque en esta coyuntura, más que en muchas otras, los acontecimientos se dan de manera acelerada, provocando constantes cambios en las relaciones, las alianzas y las posiciones políticas. Más aún, porque está en curso el derrumbe del imperio incaico. Por tanto, la actuación de Paullu y su relación con su hermano sufren un proceso de transformación en el que encontramos — sin embargo- una constante: Paullu y Manco mantienen una relación de respeto y están pendientes uno del otro sin llegar nunca a una ruptura, actuando como si se tratara de un poder en cierto modo compartido. Obviamente los restos de un antiguo poder y bajo el dominio de otro superior.

Hemos partido de la constatación que Paullu fue coronado como Inca, pero como solamente de uno de los suyos del imperio y hemos podido seguir la relación con su hermano desde este momento. Entonces se lo observa actuando con gran autoridad aunque subordinado a Manco. Luego se evidenciará su estrecha relación con la zona del Collasuyu, justamente el lugar último de la resistencia inca, fuera de Vilcabamba, por supuesto. De este modo en la historia que se puede seguir en cuatro momentos de la vida de Paullu, ligados al de la Conquista, encontramos que su actuación pasó de un total apoyo a su hermano Manco en el Cusco y objeto de la confianza de éste cuando fue enviado al Collasuyu con Vilac Umu, a una actitud de prudencia frente al conquistador y a su poderío bélico. Parece entonces que Paullu marca su independencia frente a su hermano que no se aprecia cuando estaban juntos en el Cusco. Sin embargo, si bien por un lado Paullu trata de mostrarse lo más fiel posible a los españoles, nunca deja de mantener viva la posibilidad de una resistencia ante ellos en manos de Manco. Paullu lo alienta a resistir y quizás colabora para que no sea totalmente derrotado. Al mismo tiempo los españoles siempre desconfían de él pero lo necesitan y lo lisonjean con honores y bienes. Durante el último periodo, cuando Paullu se instala en el Cusco y es bautizado, parecería que los roles se trastocan y Manco pasa a jugar el rol secundario

En esta posibilidad de diarquía, Manco asume el papel de Inca auca o guerrero y Paullu yachaj $u$ organizador y religioso. Las resonancias de su rol se hacen patentes en la figura de un hijo de Paullu, Francisco Tito Yupanqui, el escultor de la famosa Virgen de Copacabana, objeto de extendido culto.

Entonces, junto con la propuesta de diarquía están también planteadas algunas pautas de su funcionamiento, aunque fueran en momentos extremadamente difíciles.

Cuando el virrey Toledo fue al Cuzco en la década de 1570, tuvo una actitud abiertamente contraria a la élite indígena, particularmente a la inca. Inició, entonces una persecución a la 
Paullu y Manco zuna diarquía inca en tiempos de conquista?

descendencia de Paullu, quitándoles sus bienes, los reconocimientos que habían recibido de la Corona por su apoyo y apresando a Carlos, el hijo de Paullu. Aunque luego los hijos de Paullu recuperarían sus bienes, el argumento de Toledo era que encontró que los familiares de Paullu estaban actuando de acuerdo con los incas que resistían en Vilcabamba.

\section{Referencias citadas}

ARZE QUIROGA, E., 1969 - Historia de Bolivia: fases del proceso hispano-americano, orígenes de la sociedad boliviana en el siglo XVI, 465 p.; La Paz: Los Amigos del Libro.

ARZE, S. \& MEDINACELI, X., 1991 - Imágenes y presagios: el escudo de los Ayaviri, Mallkus de Charcas, 77 p.; La Paz: Hisbol.

BURGA, M., 1988 - Nacimiento de una utopía: muerte y resurrección de los Incas, 428 p.; Lima: Instituto de Apoyo Agrario.

CABELLO DE VALBOA, M., 1951 [1586] - Miscelánea Antártida. Una historia del Perú antiguo, xl + 561 p.; Lima: UNMSM. Instituto de Etnología.

CARRILLO, F., 1991 - Cronistas indios y mestizos I, 258 p.; Lima: Horizonte. Enciclopedia histórica de la literatura peruana, 6.

CHOQUE CANQUI, R., 2003 - Los Inka de Copacabana y la invasión europea. In: Ponencia presentada al 51을 Congreso Internacional de Americanistas; Chile.

CIEZA DE LEÓN, P., 1989 - Crónica del Perú: Tercera parte (Cieza de León, P. \& Cantú, F., eds.), 431 p.; Lima: Pontificia Universidad Católica del Perú - Academia Nacional de la Historia.

PIZARRO, P., 1986 [1571] - Relación del descubrimiento y conquista de los reinos del Perú (Lohmann Villena, G. \& Duviols, P., eds.), 277 p.; Lima: PUCP, Fondo editorial.

DUMBAR TEMPLE, E., 1937 - La descendencia de Huayna Cápac ( $2^{\text {ra }}$ parte). Revista Histórica, 11 (3): 284-323; Lima.

DUMBAR TEMPLE, E., 1939 - La descendencia de Huayna Cápac (3 ${ }^{\text {ra }}$ parte). Revista Histórica, 12: 204-245; Lima.

DUMBAR TEMPLE, E., 1940 - La descendencia de Huayna Cápac (4 ${ }^{\text {ta }}$ parte). Revista Histórica, 13: 31-77; Lima.

DUMBAR TEMPLE, E., 1948 - Don Carlos Inca. Revista Histórica, 17: 134-179; Lima.

DUVIOLS, P., 1979 - La dinastía de los Incas imonarquía o diarquía? Journal de la société des Américanistes, 66: 67-83; París.

DUVIOLS, P., 1980 - Algunas reflexiones acerca de la tesis de la estructura dual del poder incaico. Revista Histórica, 4 (2): 183-196; Lima.

ELLEFSEN, B., 1989 - Matrimonio y sexo en el Incario, 430 p.; La Paz: Los amigos del Libro.

ESPINOZA SORIANO, W., 1969 - El memorial de Charcas: crónica inédita de 1582, 35 p.; Lima: Universidad Nacional de Educación.

GARCILASO DE LA VEGA, Inca, 1985 [1606] - Comentarios reales de los Indios, 515 p.; Lima: Banco de Crédito.

GISBERT, T., 1994 - Iconografía y mitos indígenas en el arte, 250 p.; La Paz: Fundación BHNGisbert.

GUAMAN POMA DE AYALA, F., 1980 [1610?] - Nueva crónica y buen gobierno (Murra, J. \& Adorno, R., eds.), 1175 p.; México: IEP - Siglo veintiuno.

GUTIÉRREZ DE SANTA CLARA, P., 1905 - Quinquenarios o historia de las guerras civiles del Perú. Crónicas del Perú, T. 3, 422 p.; Madrid: Ediciones Atlas. BAE, 166.

HEMMING, J., 1970 - The conquest of the Incas, 641 p.; Londres: Macmillan \& Co. 
LAMANA, G., 1996 - Identidad y pertenencia de la nobleza cuzqueña en el mundo colonial temprano. Revista Andina: La invención del catolicismo andino, siglos XVI-XVII, 14 (1): 73-106; Cusco.

MENDOZA, G., 1938 - Año en que fue fundada la Villa de La Plata. Revista de la Universidad Mayor Real y Pontificia de San Francisco Xavier de Chuquisaca, Central de Bolivia, 17; Sucre: Ed. Charcas.

MESA, J. de, 1972 - Escultura virreinal en Bolivia, 489 p.; La Paz: Academia Nacional de Ciencias de Bolivia.

MURÚA, Fray M., 1962 [ca. 1600] - Historia general del Perú (Bellesteros, M., ed.), 571 p.; Madrid: Dastin.

PÄRSSINEN, M., 2003 - Tawantinsuyu. El estado inca y su organización política, 425 p.; Lima: IFEA, PUCP, Embajada de Finlandia.

PIZARRO, P., 1986 [1571] - Relación del descubrimiento y conquista de los reinos del Perú (Lohmann Villena, G. \& Duviols, P., eds.), 277 p.; Lima: PUCP, Fondo editorial. Segunda edición.

POLO DE ONDEGARDO, J., 1990 [1571] - El mundo de los Incas; Madrid: Ed. de Laura González y Alicia Alonso. Crónicas de América, 58.

RAMOS GAVILÁN, A., 1988 [1621] - Historia del Santuario de Nuestra Señora de Copacabana, 618 p.; Lima: P. L. Villanueva. Transcripción, nota del editor e Índics de Ignacio Prado Pastor.

SANTOS ESCOBAR, R., 1987 - La contribución de Apu Chalco Yupanqui, Gobernador del Kollasuyu en la expedición de Diego de Almagro a Copiapo, principio de Chile, vol. III, 38 p.; La Paz: Ed. Colección de folletos bolivianos de Hoy.

SANTOS, R., 1989 - Información y probanza de don Fernando Kollatupaj, Onofre Maskapongo y Juan Pizarro Limachi, Inkas de Copacabana: siglo XVII. Historia y Cultura, 16; La Paz: Ed. Don Bosco.

SOMEDA, H., 2001 - El Imperio de los Incas: imagen del Tahuantinsuyu creada por los cronistas, 327 p; Lima: PUCP, Fondo Editorial. Segunda Edición.

TITO CUSI YUPANQUI, DIEGO DE CASTRO, 1911 [1570] - Relación de la conquista del Perú y hechos del Inca Manco II. In: Enciclopedia de la Literatura Peruana; Lima: Editorial Horizonte. Cronistas Indios y Mestizos, I.

WACHTEL, N., 1971 - La visión de los vencidos: los indios del Perú frente a la conquista española (1530-1570), 408 p.; Madrid: Alianza.

WACHTEL, N., 1981 - Los mitimas del valle de Cochabamba: la política de colonización de Wayna Capac. Historia Boliviana, 1 (1): 21-57; Cochabamba.

ZUIDEMA, T., 1989 - Reyes y guerreros: ensayos de cultura andina (Burga, M., comp.), 563 p.; Lima: Asociación peruana para el fomento de las ciencias sociales. 